\title{
PERBANDINGAN RISIKO YANG BERPENGARUH TERHADAP KINERJA PADA PROYEK BANGUNAN HOTEL DAN PROYEK JALAN TOL
}

\author{
Kishin Edo Permula Karo Sekali ${ }^{1}$, M. Fadel Andika ${ }^{2}$, Kusumadi ${ }^{3}$ \\ ${ }^{1}$ Program Studi Manajemen Rekayasa Konstruksi Gedung, Politeknik Negeri Medan \\ Email: kishinpermula@students.polmed.ac.id \\ ${ }^{2}$ Program Studi Manajemen Rekayasa Konstruksi Gedung, Politeknik Negeri Medan \\ ${ }^{3}$ Program Studi Manajemen Rekayasa Konstruksi Gedung, Politeknik Negeri Medan
}

\begin{abstract}
Abstrak. Dengan adanya proyek yang sedang berjalan di balige dan parapat menimbulkan risiko berakibat tinggi bagi proyek maupun lingkungan sekitar. Tujuan penelitian ini adalah untuk mengetahui faktor - faktor risiko, tingkat risiko, hingga penanganan yang akan dilakukan terhadap faktor risiko yang dominan. Metode yang dilakukan adalah dengan melakukan penyebaran kuesioner di proyek Hotel Labersa Balige dan proyek Jalan Tol Tebing Tinggi - Parapat. Masing - masing terdiri dari pihak kontraktor, manajemen konstruksi, subkontraktor, mandor dan security. Langkah yang dilakukan dengan identifikasi risiko, dan analisis risiko, yang kemudian diolah menggunakan program aplikasi SPSS V.25. Syarat data valid dan reliabel adalah nilai validitas $\mathrm{r}_{\text {hitung }}>\mathrm{r}_{\text {tabel }}$ dan nilai cronbach's alph $>\mathrm{r}_{\text {tabel }}$. Setelah itu, risiko akan dikategorikan berdasarkan nilai Severity Index dan untuk mengetahui tingkat risiko digunakan peta profil risiko. Berdasarkan pengolahan data, pada proyek pembangunan Hotel Labersa Balige terdapat 1 faktor risiko yang paling berpengaruh terhadap pekerjaan pembangunan dengan nilai $82,67 \%$ terhadap probabilitas dan nilai $44,00 \%$ terhadap dampak sedangkan pada proyek Jalan Tol Tebing Tinggi - Parapat terdapat terdapat 2 faktor yang paling berpengaruh terhadap pekerjaan pembangunan yang pertama dengan nilai $81,76 \%$ terhadap probabilitas dan nilai $84,71 \%$ terhadap dampak dan yang kedua dengan nilai $81,76 \%$ terhadap probabilitas dan nilai $80,00 \%$ terhadap dampak.
\end{abstract}

Kata kunci: Risiko, Identifikasi Risiko, Analisis Risiko.

Diterima Redaksi: 03-10-2020 | Selesai Revisi: 09-03-2021 | Diterbitkan Online: 09-03-2021

\section{PENDAHULUAN}

Manajemen proyek adalah proses pengelolaan proyek yaitu melalui pengelolaan, pengalokasian, dan penjadwalan sumber daya dalam proyek untuk mencapai sasaran. Risiko adalah suatu keadaan yang tidak pasti dan terdapat unsur bahaya, akibat atau konsekuensi yang bisa terjadi akibat proses yang sedang berlangsung maupun kejadian yang akan datang.

Risiko kinerja proyek adalah risiko yang berkaitan dengan pelaksanaan proyek. Yang termasuk dalam risiko kinerja proyek antara lain :

1. Risiko force majeure

2. Penurunan Produktivitas Material dan Peralatan Konstruksi

3. Kemananan dan Keselamatan Kerja (K3) (Andi, 2005)

4. Akses Mobilisasi Menuju Lapangan (Djojosoedarso, 2003)

5. Design dan informasi (S.M. Mousavi et al, 2011)

6. Risiko Tenaga Kerja 
7. Risiko Kontraktual

8. Risiko Pelaksanaan

9. RisikoManajemen

Dalam pelaksanaannya, terdapat beberapa tahapan dalam manajemen risiko. Menurut Iman Soeharto (1999) mengemukan bahwa tahapan manajemen risisko merupakan pendekatan sistematis mengenai risiko yang mungkin terjadi. Kemudian pendekatan tersebut dikembangkan menjadi tahapan manajemen. Hasil dari pendekatan tersebut adalah sebagai berikut:

1. Identifikasi Risiko

2. Analisis dan evaluasi risiko

3. Respon atau reaksi untuk menanggulangi risiko

a. Menghindari risiko

b. Mencegah risiko dan mengurangi

c. Meretensi risiko

d. Mentransfer Risiko

e. Asuransi

Proyek pembangunan dapat dikatakan sebagai proyek yang berisiko tinggi mengingat besarnya bobot pekerjaan dan tingginya struktur yang akan dibangun. Proses konstruksi pada proyek biasanya memakan waktu cukup lama dan kompleks sehingga dapat menimbulkan ketidakpastian yang pada akhirnya akan memunculkan berbagai macam risiko. Dampak risiko dapat mempengaruhi produktivitas, prestasi (performance), kualitas, dan anggaran biaya proyek. Hubungan kinerja dan risiko adalah manajemen risiko membantu perusahaan dalam membuat cadangan atau alternatif suatu proyek perusahaan sehingga ketika perusahaan tersebut mengalami suatu risiko perusahaan tersebut sudah mengantisipasi munculnya risiko tersebut dengan cadangan atau alternatif yang telah dibuat.

Berdasarkan penjelasan di atas, peneliti tertarik untuk membahas lebih jauh mengenai "Perbandingan Risiko Yang berpengaruh Terhadap Kinerja Pada Proyek Bangunan Hotel Dan Proyek Jalan Tol”. Adapun tujuan penelitian untuk mengidentifikasi risiko-risiko yang mungkin terjadi dalam pelaksanaan proyek pembangunan Hotel Labersa Balige dan pelaksanaan proyek pembangunan Jalan Tol Tebing TinggiParapat.

\section{METODE PENELITIAN}

Adapun tahapan yang akan dilakukan pada pembuatan penelitian ini dapat dilihat pada Gambar 1 berikut. 


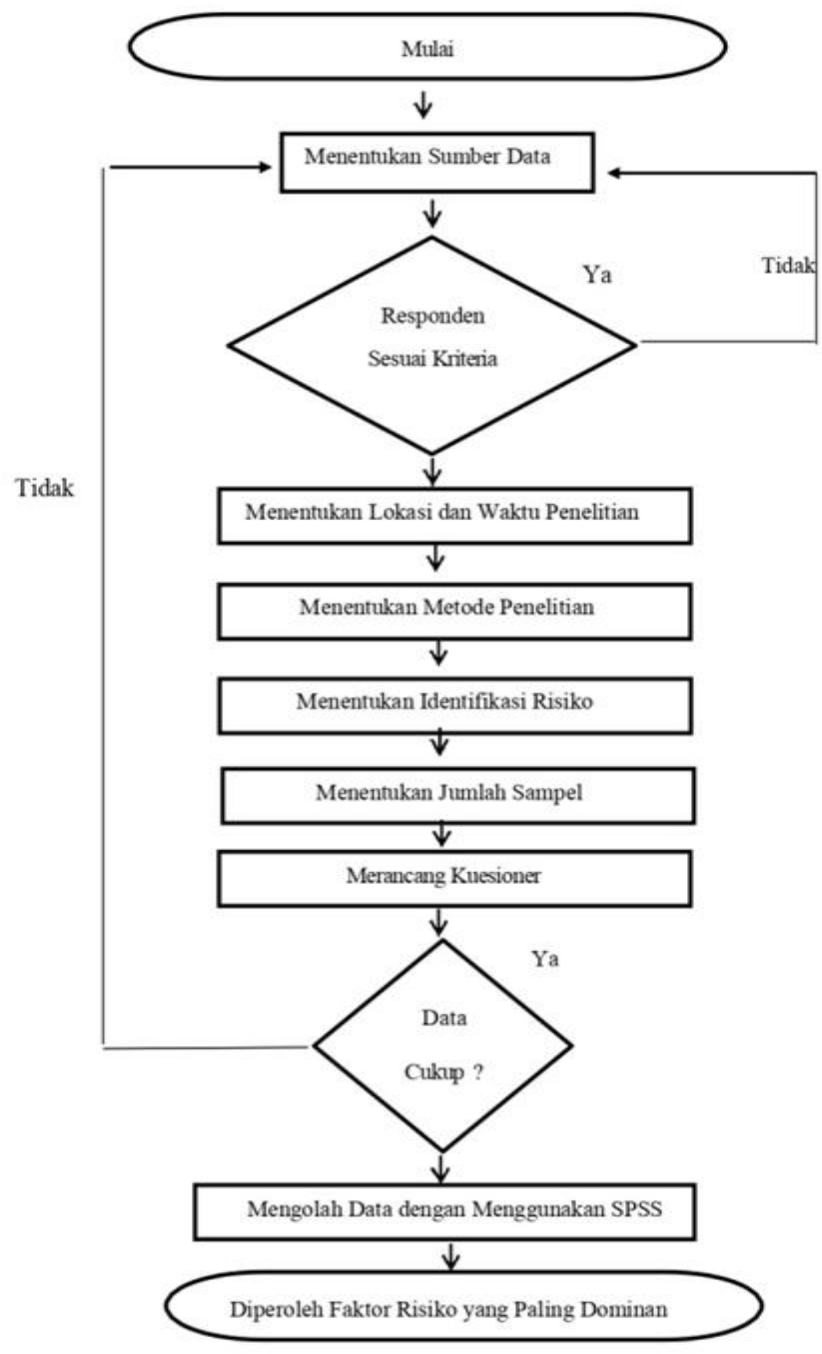

Gambar 1. Diagram Alir Pelaksanaan Penelitian.

\section{HASIL DAN PEMBAHASAN}

\section{Analisis data}

\section{Uji Validitas}

Uji validitas dapat dilakukan dengan dua cara yaitu dengan korelasi Bivariate Pearson (Produk Momen Pearson) dan Corrected Item-Total Correlation (Priyanto, 2008). Uji validitas ini dilakukan dengan membandingkan nilai r-hitung SPSS dengan nilai $r$ table Product Moment. Berdasarkan uji dua sisi (2-tailed) dengan taraf signifikansi 5\% maka diperoleh nilai $r$ tabel untuk $\mathrm{df}=30-2=28$ responden adalah 0,374 untuk proyek pembangunan Hotel Labersa dan $\mathrm{df}=34-2=32$ responden adalah 0.349 untuk proyek pembangunan Jalan Tol Tebing Tinggi - Parapat.

\section{Uji Reliabilitas}

Uji reliabilitas dilakukan dengan menggunakan nilai Cronbach's alpha yang terdapat pada SPSS versi 25. Dari hasil pengujian dilakukan analisis terhadap angka yang didapatkan dengan membandingkannya terhadap nilai r- tabel. 


\section{Saverity Index}

Berdasarkan perhitungan dengan menggunakan Microsoft Excel, maka untuk nilai Severity Index pada proyek pembangunan Hotel Labersa Balige dapat dilihat seperti pada Tabel 1 berikut.

Tabel 1. Saverity Index Hotel Labersa Balige

\begin{tabular}{|c|c|c|c|c|c|c|}
\hline \multirow[t]{2}{*}{$\begin{array}{l}\text { Kode } \\
\text { Risiko }\end{array}$} & \multicolumn{4}{|c|}{$\begin{array}{c}\text { Skala } \\
\text { Tingkat } \\
\text { Risiko }\end{array}$} & \multirow{2}{*}{$\begin{array}{c}\text { Tingkat } \\
\text { Risiko } \\
\text { (PXI) }\end{array}$} & \multirow[t]{2}{*}{ Ket. Tingkat Risiko } \\
\hline & Probabilitas (P) & Dampak (I) & $\mathbf{P}$ & I & & \\
\hline R1 & 36,67 & 40,00 & 2 & 3 & 6 & Sedang \\
\hline $\mathrm{R} 2$ & 36,00 & 60,00 & 2 & 3 & 6 & Sedang \\
\hline R3 & 40,00 & 45,33 & 2 & 3 & 6 & Sedang \\
\hline $\mathrm{R} 4$ & 82,67 & 44,00 & 5 & 3 & 15 & Tinggi \\
\hline R5 & 40,00 & 48,00 & 2 & 3 & 6 & Sedang \\
\hline R6 & 47,33 & 55,33 & 3 & 3 & 9 & Sedang \\
\hline R7 & 40,67 & 43,33 & 3 & 3 & 9 & Sedang \\
\hline $\mathrm{R} 8$ & 47,33 & 46,00 & 3 & 3 & 9 & Sedang \\
\hline R9 & 47,33 & 50,00 & 3 & 3 & 9 & Sedang \\
\hline $\mathrm{R} 10$ & 40,00 & 45,33 & 2 & 3 & 6 & Sedang \\
\hline $\mathrm{R} 11$ & 42,67 & 44,00 & 3 & 3 & 9 & Sedang \\
\hline $\mathrm{R} 12$ & 46,00 & 48,67 & 3 & 3 & 9 & Sedang \\
\hline $\mathrm{R} 13$ & 38,67 & 42,67 & 2 & 3 & 6 & Sedang \\
\hline $\mathrm{R} 14$ & 38,67 & 50,00 & 2 & 3 & 6 & Sedang \\
\hline $\mathrm{R} 15$ & 30,67 & 32,67 & 2 & 3 & 6 & Sedang \\
\hline R16 & 38,67 & 34,67 & 2 & 3 & 6 & Sedang \\
\hline $\mathrm{R} 17$ & 38,67 & 42,00 & 2 & 3 & 6 & Sedang \\
\hline $\mathrm{R} 18$ & 35,33 & 38,67 & 2 & 3 & 6 & Sedang \\
\hline R19 & 40,67 & 48,00 & 3 & 3 & 9 & Sedang \\
\hline R20 & 40,67 & 50,67 & 3 & 3 & 9 & Sedang \\
\hline $\mathrm{R} 21$ & 46,67 & 50,00 & 3 & 3 & 9 & Sedang \\
\hline $\mathrm{R} 22$ & 36,67 & 39,33 & 2 & 3 & 6 & Sedang \\
\hline $\mathrm{R} 23$ & 42,67 & 50,00 & 3 & 3 & 9 & Sedang \\
\hline $\mathrm{R} 24$ & 43,33 & 46,00 & 3 & 3 & 9 & Sedang \\
\hline $\mathrm{R} 25$ & 44,00 & 44,00 & 3 & 3 & 9 & Sedang \\
\hline $\mathrm{R} 26$ & 39,33 & 42,00 & 2 & 3 & 6 & Sedang \\
\hline $\mathrm{R} 27$ & 36,67 & 32,00 & 2 & 2 & 4 & Rendah \\
\hline R28 & 44,00 & 44,00 & 3 & 3 & 9 & Sedang \\
\hline R29 & 36,67 & 45,33 & 2 & 3 & 6 & Sedang \\
\hline R30 & 36,00 & 48,67 & 2 & 3 & 6 & Sedang \\
\hline R31 & 34,67 & 36,80 & 2 & 3 & 6 & Sedang \\
\hline R32 & 38,67 & 40.67 & 2 & 3 & 6 & Sedang \\
\hline R33 & 34,00 & 48,00 & 2 & 3 & 6 & Sedang \\
\hline R34 & 39,33 & 36,67 & 2 & 2 & 4 & Rendah \\
\hline R35 & 42,67 & 39,33 & 3 & 3 & 9 & Sedang \\
\hline R36 & 36,00 & 37,33 & 2 & 2 & 4 & Rendah \\
\hline R37 & 40,67 & 52,00 & 3 & 3 & 9 & Sedang \\
\hline R38 & 41,33 & 57,33 & 3 & 3 & 9 & Sedang \\
\hline R39 & 35,33 & 72,67 & 2 & 4 & 8 & Sedang \\
\hline $\mathrm{R} 40$ & 28,00 & 66,00 & 2 & 4 & 8 & Sedang \\
\hline $\mathrm{R} 41$ & 41,33 & 48,00 & 3 & 3 & 9 & Sedang \\
\hline $\mathrm{R} 42$ & 48,67 & 56,00 & 3 & 3 & 9 & Sedang \\
\hline $\mathrm{R} 43$ & 41,33 & 56,00 & 3 & 3 & 9 & Sedang \\
\hline $\mathrm{R} 44$ & 31,33 & 37,33 & 2 & 2 & 4 & Rendah \\
\hline $\mathrm{R} 45$ & 46,00 & 50,00 & 3 & 3 & 9 & Sedang \\
\hline $\mathrm{R} 46$ & 34,67 & 55,33 & 2 & 3 & 6 & Sedang \\
\hline $\mathrm{R} 47$ & 34,67 & 52,67 & 2 & 3 & 6 & Sedang \\
\hline $\mathrm{R} 48$ & 31,33 & 50,00 & 2 & 3 & 6 & Sedang \\
\hline
\end{tabular}




\begin{tabular}{lcccccc}
\hline \multirow{2}{*}{$\begin{array}{l}\text { Kode } \\
\text { Risiko }\end{array}$} & Nilai Severity Index & & \multicolumn{2}{c}{$\begin{array}{c}\text { Skala } \\
\text { Tingkat } \\
\text { Risiko }\end{array}$} & $\begin{array}{c}\text { Tingkat } \\
\text { Risiko }\end{array}$ & \multirow{2}{*}{ Ket. Tingkat Risiko } \\
\cline { 2 - 5 } & Probabilitas (P) & Dampak (I) & P & I & (PXI) & \\
\hline R49 & 36,00 & 42,67 & 2 & 3 & 6 & Sedang \\
R50 & 44,00 & 45,33 & 3 & 3 & 9 & Sedang \\
R51 & 46,00 & 46,67 & 3 & 3 & 9 & Sedang \\
R52 & 41,33 & 58,00 & 3 & 3 & 9 & Sedang \\
R53 & 46,00 & 57,33 & 3 & 3 & 9 & Sedang \\
\hline R54 & 42,67 & 54,00 & 3 & 3 & 9 & Sedang \\
\hline
\end{tabular}

Sedangkan nilai Severity index proyek pembangunan Jalan Tol Tebing Tinggi - Parapat yang dapat dilihat seperti pada Tabel 2 berikut.

Tabel 2. Saverity Index Jalan Tol Tebing Tinggi - Parapat

\begin{tabular}{|c|c|c|c|c|c|c|}
\hline \multirow[t]{2}{*}{$\begin{array}{l}\text { Kode } \\
\text { Risiko }\end{array}$} & \multicolumn{4}{|c|}{$\begin{array}{c}\text { Skala } \\
\text { Tingkat } \\
\text { Risiko }\end{array}$} & \multirow{2}{*}{$\begin{array}{c}\text { Tingkat } \\
\text { Risiko } \\
\text { (PXI) }\end{array}$} & \multirow[t]{2}{*}{ Ket. Tingkat Risiko } \\
\hline & Probabilitas $(\mathbf{P})$ & Dampak (I) & $\mathbf{P}$ & I & & \\
\hline $\mathrm{R} 1$ & 44,12 & 68,24 & 3 & 4 & 12 & Tinggi \\
\hline $\mathrm{R} 2$ & 32,35 & 58,82 & 2 & 3 & 6 & Sedang \\
\hline R3 & 44,12 & 68,24 & 3 & 4 & 12 & Tinggi \\
\hline $\mathrm{R} 4$ & 81,76 & 84,71 & 5 & 5 & 25 & Sangat Tinggi \\
\hline $\mathrm{R} 5$ & 81,76 & 55,88 & 5 & 3 & 15 & Tinggi \\
\hline R6 & 61,76 & 84,71 & 4 & 5 & 20 & Sangat Tinggi \\
\hline R7 & 57,65 & 53,53 & 3 & 3 & 9 & Sedang \\
\hline $\mathrm{R} 8$ & 42,94 & 51,18 & 3 & 3 & 9 & Sedang \\
\hline R9 & 61,18 & 55,29 & 4 & 3 & 9 & Tinggi \\
\hline $\mathrm{R} 10$ & 43,53 & 53,53 & 3 & 3 & 9 & Sedang \\
\hline $\mathrm{R} 11$ & 81,76 & 53,53 & 5 & 3 & 9 & Tinggi \\
\hline $\mathrm{R} 12$ & 64,12 & 81,76 & 4 & 5 & 20 & Sangat Tinggi \\
\hline $\mathrm{R} 13$ & 44,12 & 62,35 & 3 & 4 & 12 & Tinggi \\
\hline $\mathrm{R} 14$ & 30,59 & 72,35 & 2 & 4 & 8 & Sedang \\
\hline $\mathrm{R} 15$ & 30,59 & 52,35 & 2 & 3 & 6 & Sedang \\
\hline $\mathrm{R} 16$ & 30,00 & 51,18 & 2 & 3 & 6 & Sedang \\
\hline $\mathrm{R} 17$ & 45,29 & 56,47 & 2 & 3 & 6 & Sedang \\
\hline $\mathrm{R} 18$ & 55,28 & 66,47 & 2 & 4 & 8 & Sedang \\
\hline R19 & 48,82 & 72,94 & 3 & 4 & 12 & Tinggi \\
\hline $\mathrm{R} 20$ & 30,59 & 68,82 & 2 & 4 & 8 & Sedang \\
\hline $\mathrm{R} 21$ & 58,82 & 50,59 & 3 & 3 & 9 & Sedang \\
\hline $\mathrm{R} 22$ & 56,47 & 80,59 & 3 & 5 & 15 & Sangat Tinggi \\
\hline $\mathrm{R} 23$ & 65,88 & 88,82 & 4 & 5 & 20 & Sangat Tinggi \\
\hline $\mathrm{R} 24$ & 58,24 & 72,94 & 3 & 4 & 12 & Tinggi \\
\hline $\mathrm{R} 25$ & 58,82 & 58,82 & 3 & 3 & 9 & Sedang \\
\hline $\mathrm{R} 26$ & 54,71 & 72,35 & 3 & 4 & 12 & Tinggi \\
\hline $\mathrm{R} 27$ & 35,88 & 60,59 & 2 & 4 & 8 & Sedang \\
\hline $\mathrm{R} 28$ & 45,88 & 57,65 & 3 & 3 & 9 & Sedang \\
\hline R29 & 32,35 & 77,65 & 2 & 4 & 8 & Sedang \\
\hline $\mathrm{R} 30$ & 32,35 & 72,94 & 2 & 4 & 8 & Sedang \\
\hline $\mathrm{R} 31$ & 32,35 & 70,00 & 2 & 4 & 8 & Sedang \\
\hline $\mathrm{R} 32$ & 44,12 & 61,76 & 3 & 4 & 12 & Tinggi \\
\hline R33 & 43,53 & 64,12 & 3 & 4 & 12 & Tinggi \\
\hline R34 & 50,00 & 55,88 & 3 & 3 & 9 & Sedang \\
\hline R35 & 41,76 & 53,53 & 3 & 3 & 9 & Sedang \\
\hline
\end{tabular}




\begin{tabular}{|c|c|c|c|c|c|c|}
\hline \multirow[t]{2}{*}{$\begin{array}{l}\text { Kode } \\
\text { Risiko }\end{array}$} & \multicolumn{2}{|c|}{ Nilai Severity Index } & \multicolumn{2}{|c|}{$\begin{array}{c}\text { Skala } \\
\text { Tingkat } \\
\text { Risiko }\end{array}$} & \multirow{2}{*}{$\begin{array}{c}\text { Tingkat } \\
\text { Risiko } \\
\text { (PXI) }\end{array}$} & \multirow[t]{2}{*}{ Ket. Tingkat Risiko } \\
\hline & Probabilitas (P) & Dampak (I) & $\mathbf{P}$ & I & & \\
\hline R36 & 40,00 & 52,94 & 3 & 3 & 9 & Sedang \\
\hline $\mathrm{R} 37$ & 41,76 & 66,47 & 3 & 4 & 12 & Tinggi \\
\hline R38 & 31,76 & 64,71 & 2 & 4 & 8 & Sedang \\
\hline R39 & 30,59 & 78,82 & 2 & 4 & 8 & Sedang \\
\hline $\mathrm{R} 40$ & 30,00 & 68,24 & 2 & 4 & 8 & Sedang \\
\hline $\mathrm{R} 41$ & 40,00 & 72,94 & 3 & 4 & 12 & Tinggi \\
\hline $\mathrm{R} 42$ & 46,47 & 67,65 & 3 & 4 & 12 & Tinggi \\
\hline $\mathrm{R} 43$ & 42,35 & 69,41 & 3 & 4 & 12 & Tinggi \\
\hline $\mathrm{R} 44$ & 40,00 & 53,53 & 3 & 3 & 9 & Sedang \\
\hline $\mathrm{R} 45$ & 39,41 & 74,12 & 2 & 4 & 8 & Sedang \\
\hline $\mathrm{R} 46$ & 32,35 & 78,82 & 2 & 4 & 8 & Sedang \\
\hline $\mathrm{R} 47$ & 38,82 & 78,82 & 2 & 4 & 8 & Sedang \\
\hline $\mathrm{R} 48$ & 47,65 & 65,29 & 3 & 3 & 9 & Sedang \\
\hline $\mathrm{R} 49$ & 32,35 & 65,53 & 2 & 3 & 6 & Sedang \\
\hline R50 & 41,18 & 68,24 & 3 & 3 & 9 & Sedang \\
\hline R51 & 51,18 & 71,18 & 3 & 4 & 12 & Tinggi \\
\hline R52 & 42,94 & 77,06 & 3 & 4 & 12 & Tinggi \\
\hline R53 & 81,76 & 80,00 & 5 & 5 & 25 & Sangat Tinggi \\
\hline $\mathrm{R} 54$ & 29,41 & 78,24 & 2 & 4 & 8 & Sedang \\
\hline
\end{tabular}

Berdasarkan Tabel 1 dan 2 di atas dapat disimpulkan bahwa pada proyek pembangunan Hotel Labersa Balige yang memiliki hasil perkalian antara dua variabel dengan nilai tertinggi adalah pada R4 yaitu faktor cuaca yang tidak menentu sedangkan berdasarkan Tabel IV.28 di atas dapat disimpulkan bahwa pada proyek pembangunan Jalan Tol Tebing Tinggi - Parapat yang memiliki hasil perkalian antara dua variable dengan niali tertinggi adalah $\mathrm{R} 4, \mathrm{R} 53$. Setelah didapatkan nilai dari perkalian dua variabel kemudian dikelompokkan ke dalam kategori risiko.

\section{Penanganaan Risiko}

Dari hasil olah data yang telah dilakukan, maka tingkat risiko yang paling tinggi yakni cuaca yang tidak menentu (R4). Tindakan yang dapat dilakukan untuk meretensi faktor risko tersebut adalah dengan memprediksi cuaca dan perencanaan pengerjaan proyek. Perencanaan pengerjaan proyek dibagi ke dalam 3 (tiga) bagian, yakni: pengerjaan jangka panjang dan pengerjaan jangka pendek.

1. Pada pengerjaan proyek jangka panjang sebaiknya dimulai di akhir musim penghujan atau pada masa peralihan antara musim hujan dan musim kemarau, yakni sekitar bulan April hingga Mei. Misalnya pada pengerjaan tanah atau pondasi yang biasanya mengawali sebuah proyek sangat berpengaruh terhadap cuaca karena pengerjaan ini harus segera diselesaikan agar dapat melanjutkan pekerjaan yang lain tanpa hambatan dan dapat sesuai dengan perencanaan waktu. Contoh lainnya adalah pekerjaan dinding sebaiknya dilakukan sebelum musim penghujan tiba. Jika dilakukan pada musim penghujan, tidak saja pengerjaan akan berjalan lambat tetapi juga kualitas dinding menjadi kurang baik. Dinding akan menjadi karena curah hujan yang tinggi, sehingga akan berpengaruh pada proses pengecatan. Apabila cuaca yang tidak menentu 
berpengaruh terhadap perencanaan pekerjaan yang telah dibuat, lakukan dokumentasi kejadian sebagai bukti untuk melakukan negosiasi kepada pihak owner agar tidak terjadi kerugian pada proyek, terkhususnya pada waktu dan biaya.

2. Pada pengerjaan proyek jangka pendek bisa dilakukan pada musim penghujan tetapi dengan memanfaatkan masa kering yang terjadi pada musim hujan. Pada masa kering ini, curah hujan tidak lagi tinggi, sehingga tidak begitu menghambat pekerjaan - pekerjaan yang harus dilakukan. Adapun hal yang dapat dilakukan untuk mengantisipasi kembali cuaca yang buruk antara lain:

a. Mempersiapkan tenda khusus, misalnya untuk peralatan, material, dan juga untuk para pekerja.

b. Pemasangan terpal pada area-area kerja tertentu yang dikhawatirkan rusak atau membahayakan jika terkena hujan.

c. Menyiapkan lampu pijar dan bowler fan untuk membantu proses pengeringan bagian-bagian yang harus kering.

d. Pemasangan penangkal petir demi melindungi para pekerja

3. Untuk mewujudkan ketepatan pekerjaan konstruksi (jadwal dan kualitas) (R53) harus memiliki perencanaan yang sangat sesuai dengan pekerjaan. Adapun hal yang dapat dilakukan untuk mengantisipasi kondisi ketepatan pekerjaan konstruksi (jadwal dan kualitas) antara lain :

a. Menyusun dengan baik perencanaan yang akan digunakan untuk pelaksanaan proyek, karena dengan adanya perencanaan dapat menghilangkan atau mengurangi ketidakpastian seperti mengetahui apa langkah terbaik yang harus dilakukan dalam pelaksanaan proyek, sumber daya apa yang diperlukan, dan apa yang menjadi target dari perencanaan tersebut yang menjadi jelas bagi setiap orang.

b. Setelah perencanaan direalisasikan maka harus dilakukan pengawasan yang baik agar perencanaan sesuai dengan yang diharapkan.

\section{SIMPULAN}

Adapun simpulan yang diperoleh dari hasil dan pembahasan antara lain:

1. Berdasarkan hasil identifikasi faktor risiko dengan menggunakan validitas dan reliabilitas pada proyek Hotel Labersa Balige diperoleh 1 (satu) kelompok variabel risiko yang berpengaruh terhadap kinerja proyek pada pembangunan Hotel Labersa Balige yaitu risiko Force Majeure (cuaca yang tidak menentu) sedangkan pada proyek pembangunan Jalan Tol Tebing Tinggi Parapat diperoleh beberapa kelompok variabel risiko yang berpengaruh terhadap kinerja yaitu Risiko Force Majeure (cuaca yang tidak menentu) dan Risiko Manajemen (ketepatan pekerjaan konstruksi (jadwal dan kualitas).

2. Proses penanganan risiko yang dilakukan terhadap faktor risiko yang dominan yaitu melakukan retensi terhadap risiko. Sehingga dapat memperkecil kemungkinan terjadinya kerugian dan mengurangi keparahan bila suatu risiko memang terjadi kaku. 


\section{DAFTAR PUSTAKA}

Djojosoedarso, S. 2003. Prinsip-Prinsip Manajemen Risiko dan Asuransi. Jakarta: Salemba Empat.

Kerzner, Harold Ph.. 2009. Project Management: A systems Approach To Planning, Scheduling And Controlling, Tenth Editon. New York.

PMI (Project Management Institute). 2004. A Guide to the Project Management Body of Knowledge (PMBOK Guide). 3rd edition, Newtown Square, Pennsylvania, USA.

Soeharto, Iman. 1999. Manajemen Proyek Dari Konseptual Sampai Operasional. Jakarta: Erlangga.

Soeharto, Iman. 2001. Manajemen Proyek Dari Konseptual Sampai Operasional Jilid 2. Jakarta: Erlangga.

Soemarno. 2008. Manajemen Resiko Proyek Kontruksi, Resiko dan Analisisnya. 